\title{
Day-to-Day Variability of Parameters Recorded by Home Noninvasive Positive Pressure Ventilation for Detection of Severe Acute Exacerbations in COPD
}

International Journal of Chronic Obstructive Pulmonary Disease

\author{
Weipeng Jiang $\mathbb{( D}^{1, *}$ \\ Yencheng Chaol,* \\ Xiaoyue Wang' \\ Cuicui Chen' \\ Jian Zhou (D) \\ Yuanlin Song ${ }^{1-5}$
}

'Department of Pulmonary Medicine, Zhongshan Hospital, Fudan University, Shanghai, 200032, People's Republic of China; ${ }^{2}$ Department of Pulmonary Medicine, Shanghai Respiratory Research Institute, Shanghai, 200032, People's Republic of China; ${ }^{3}$ National Clinical Research Center for Aging and Medicine, Huashan Hospital, Fudan University, Shanghai, 200000, People's Republic of China; ${ }^{4}$ Department of Pulmonary Medicine, Zhongshan Hospital, Qingpu Branch, Fudan University, Shanghai, 201700, People's Republic of China; ${ }^{5}$ Department of Pulmonary Medicine, Jinshan Hospital of Fudan University, Shanghai, 20I508, People's Republic of China

*These authors contributed equally to this work
Background: Home noninvasive positive pressure ventilation (NPPV) can be considered not only as an evidence-based treatment for stable hypercapnic chronic obstructive pulmonary disease (COPD) patients, but also as a predictor for detecting severe acute exacerbations of chronic obstructive pulmonary disease (AECOPD).

Methods: In this retrospective observational study, we collected clinical exacerbations information and daily NPPV-related data in a cohort of COPD patients with home NPPV for 6 months. Daily changes in NPPV-related parameters' variability prior to AECOPD were examined using two-way repeated measures ANOVA and individual abnormal values $(>75$ th or $<25$ th percentile of individual baseline parameters) were calculated during 7-day preAECOPD period. Multivariate logistic regression was used to identify the independent risk factors associated with AECOPD that then were incorporated into the nomogram.

Results: Between January 1, 2018, and January 1, 2020, a total of 102 patients were included and 31 (30.4\%) participants experienced hospitalization (AECOPD group) within 6 months. Respiratory rate changed significantly from baseline at 1, 2 or 3 days prior to admission ( $\mathrm{p}<0.001$, respectively) in the AECOPD group. The number of days with abnormal values of daily usage, leaks, or tidal volume during the 7-day pre-AECOPD period in the AECOPD group was higher than in the stable group $(\mathrm{p}<0.001$, respectively). On multivariate analysis, 7-day mean respiratory rate (OR 1.756, 95\% CI 1.249-2.469), abnormal values of daily use (OR 1.918, 95\% CI 1.253-2.934) and tidal volume (OR 2.081, 95\% CI 1.380-3.140 ) within 7 days were independently associated with the risk of AECOPD. Incorporating these factors, the nomogram achieved good concordance indexes of 0.962 .

Conclusion: Seven-day mean respiratory rate, abnormal values of daily usage, leaks, and tidal volume within the 7-day pre-AECOPD period may be biomarkers for detection of AECOPD.

Keywords: noninvasive positive pressure ventilation, day-to-day variability, detection, acute exacerbations of COPD

\section{Introduction}

Acute exacerbations of chronic obstructive pulmonary disease (AECOPD) are defined as episodes of worsening of respiratory symptoms that result in additional therapy. ${ }^{1,2}$ Hospitalization for a severe AECOPD is associated with worse health status, faster disease progression, poor prognosis, and increased mortality risk. ${ }^{1,3-5}$ 
Furthermore, COPD is associated with a significant healthcare burden and AECOPD-related hospitalizations account for the greatest proportion. ${ }^{6}$ Therefore, early recognition of AECOPD and prompt therapeutic interventions aimed at reducing the frequency and severity of AECOPD is of paramount importance for better outcomes. ${ }^{7}$

Some observational studies using symptoms, ${ }^{8}$ patientreported diaries ${ }^{9}$ or feasible clinical physiological parameters, such as respiratory rate, ${ }^{10}$ pulse-oximetry, ${ }^{1,12}$ respiratory sounds ${ }^{13}$ and lung function measured by the forced oscillation technique (FOT), ${ }^{14}$ have shown progress in recognition of AECOPD. However, interventional trials including home telemonitoring of respiratory parameters, ${ }^{15}$ vital signs on a daily basis, ${ }^{16}$ symptoms questionnaire and oxygen saturation, ${ }^{17-19}$ cardiac parameters and $\mathrm{FOT}^{20}$ for early detection AECOPD have provided diverse outcomes. Daily monitoring of some parameters may be too variable to be useful in clinical management.

Home noninvasive positive pressure ventilation (NPPV) has become standard evidence-based care for stable hypercapnic COPD patients. ${ }^{21-25}$ Many ventilatory devices are embedded with built-in software, which enables collection and provision of ventilatory parameters and physiological indices. There may be significant findings in evaluating the day-to-day variability of parameters recorded by home NPPV prior to AECOPD, as physiological variations alter with disease. Home NPPV can be considered not only as a treatment, but also as a telemonitoring predictor for objectively detecting AECOPD onset. $^{26}$ Furthermore, this approach requires neither additional sensors in the patient's environment nor the patient's active daily intervention. Borel et al. ${ }^{27}$ demonstrated that daily variations in respiratory rate and percentage of respiratory cycles triggered by the patient might be associated with the onset of AECOPD. Blouet et al. ${ }^{28}$ also showed that changes in breathing patterns might predict severe AECOPD. Nevertheless, the above studies focused on a single predicting factor, which might lead to an inefficiency of prediction. Clear forecasting methods that incorporate multiple parameters associated with home NPPV are lacking.

In this study, we retrospectively collected daily NPPVrelated data and clinical exacerbations information in a cohort of COPD patients who required home NPPV for 6 months. Our objective was (1) to evaluate the AECOPD predictive efficiency of day-to-day variation in respiratory rate, daily usage, leaks, and tidal volume recorded by the ventilators; and (2) to establish a multiple parameters prediction model.

\section{Methods}

\section{Study Design and Patient Characteristics}

This retrospective observational study was conducted in Zhongshan Hospital Fudan University and a regional NPPV provider's database (Yichang Medical Technology Co., Ltd, Shanghai). The study was approved by the Medical Ethics committee of Zhongshan Hospital Fudan University (B2017-176) and all patients provided written informed consent. This study was conducted in accordance with the Declaration of Helsinki.

Patients were recruited according to the following inclusion criteria: (1) severe COPD patients defined clinically by forced expiratory volume in $1 \mathrm{~s}$ (FEV1)/forced vital capacity $(\mathrm{FVC})<70 \%$ and $\mathrm{FEV}<50 \%$ of predicted value after bronchodilator inhalation; ${ }^{29}$ (2) combined with chronic respiratory failure $\left(\mathrm{PaCO}_{2}>50 \mathrm{mmHg}\right)$ at last AECOPD-related hospitalizations; (3) using home NPPV and oxygen therapy for $>6$ months after discharge. Exclusion criteria comprised low compliance (defined by mean compliance of $<4 \mathrm{~h} /$ night), missing NPPV-related data $>50 \%$ within entire follow-up period, any disease impairing ventilatory function other than COPD and uncontrolled cardiac, liver, or renal insufficiency.

\section{Follow-Up and Data Collection}

For each participant, clinical assessment was obtained from medical records from last hospitalization in the hospital, including anthropometric data, smoking and exacerbation history, arterial blood gas and lung function measures. The patients were followed up for 6 months after discharge and AECOPD-related admissions were retrospectively collected. General therapy for COPD patients, such as pharmacological therapy, are standardized according to the national treatment guidelines. Pharmacological therapy is guided by symptoms, risk of exacerbation, side effects, comorbidities, and the patient's response. The diagnosis of AECOPD and the decision to admission were made according to standardized clinical guidelines $^{1,25,29}$ by the attending pulmonologist who was not one of the investigators. The date of severe AECOPD, assessed via medical records, was defined as the date of admission. Based on AECOPD-related admission, participants were divided into AECOPD group (experienced 
hospitalization over the follow-up) and stable COPD group (without exacerbation).

All day-to-day NPPV-related data (Curative Lotus ST30 or ResMed S9 VPAP $^{\mathrm{TM}} \mathrm{ST}$ ) were extracted from the memory card of the ventilator's built-in software (ResScan v5.7.0) for subsequent analysis. Downloaded data covered the entire 6 months follow-up period.

\section{Data Processing of Data Recorded by Ventilators}

Parameters downloaded by NPPV software included respiratory rate, daily usage, leaks, and tidal volume. They were displayed as 24-hour values. The baseline of NPPV-related parameters was defined as the clinical stable state period (entire follow-up period with valid recorded data excluding the pre-AECOPD period). Mean, standard deviation (SD) and quartiles of baseline parameters of each patient were calculated.

Each onset of severe AECOPD was assigned as day 0 according to the date of admission. There is a hypothesis that any changes leading up to an AECOPD would not have occurred as early as 7 days prior to the AECOPD. ${ }^{14}$ The 7 days preceding AECOPD were defined as the preAECOPD period. In stable COPD patients who were not hospitalized during follow-up, pre-exacerbation period was assumed as the last 7 days of follow-up.

To detect the timing of changes in variability of data recorded by ventilators during the pre-AECOPD period, overlapping running 7-day windows were used to examine these changes with a finer time resolution. ${ }^{14}$ For example, mean and SD value of data on day -1 were calculated for the period ranging from day -7 to -1 before AECOPD onset. The windowing proceeded in a similar manner for the rest of pre-AECOPD period (i.e. day -7 corresponds to the period from day -13 to -7 ).

For a given day, when the value of a parameter was $>75$ th or $<25$ th percentile of individual baseline parameters, the day was recorded as an abnormal value. ${ }^{27}$ The number of days with abnormal value during the 7-day pre-AECOPD period were recorded.

\section{Statistical Analysis}

All statistical analyses were performed using SPSS software (version 25.0, IBM SPSS) and R version 4.0.2 (The R Project for Statistical Computing, www.r-project.org), with statistical significance defined as two-sided $\mathrm{p}<0.05$.
Continuous variables were presented as mean and SD for normally distributed data or median and interquartile range (IQR) for non-normally distributed data. Categorical variables were presented as absolute numbers and percentages. Differences in continuous variables between two groups (AECOPD and Stable COPD) were tested with the Student t-tests or Mann-Whitney $U$-test as appropriate. The categorical variables were compared by chi-square tests or Fisher's exact tests as appropriate.

We used two-way repeated measures ANOVA to examine daily changes of the parameters in the days prior to AECOPD and Dunnett's post hoc test was used to compare each day with the baseline in each group. We then generated receiver-operator characteristic (ROC) curves to assess the discriminating power of the change or abnormal value of NPPV-related parameters in detecting AECOPD.

To establish a multiple parameters prediction model, multivariate logistic regression analysis was performed to identify predictors for AECOPD and a nomogram was performed based on the results by using the rms package of $\mathrm{R}$. The predictive performance of the nomogram was assessed by concordance index ( $\mathrm{C}$ index) and calibration with 1000 bootstrap samples. For clinical use of the model, ROC curve was formulated based on total scores of the nomogram.

\section{Results}

\section{Patients' Characteristics}

Between January 1, 2018, and January 1, 2020, 238 patients attended the study enrolment visit and a total of 102 patients were included in the final analysis (Figure 1). The analyzed cohort had severe COPD (FEV1/FVC 46.79 $\pm 9.92 \%$, \%predicted FEV1 25.87 $\pm 9.18 \%$ ) combined with chronic respiratory failure $\left(\mathrm{PaCO}_{2} 66.80 \pm 12.12 \mathrm{mmHg}\right)$ at last hospitalization. NPPV was initiated by bi-level positive airway pressure (BiPAP) in the spontaneous/timed mode. The median NPPV settings at hospital discharge were an inspiratory positive airway pressure of $16 \mathrm{~cm} \mathrm{H}_{2}$ $\mathrm{O}$ (IQR, $15-18 \mathrm{~cm} \mathrm{H}_{2} \mathrm{O}$ ), an expiratory positive airway pressure of $5 \mathrm{~cm} \mathrm{H} \mathrm{H}_{2} \mathrm{O}\left(\mathrm{IQR}, 4-5 \mathrm{~cm} \mathrm{H}_{2} \mathrm{O}\right.$ ), and a backup rate of 14 breaths/minute (IQR, 12-15 breaths/minute). During follow-up, patients had been receiving NPPV therapy for $429.73 \pm 119.26 \mathrm{~min} /$ day on average. In terms of AECOPD, 31 (30.4\%) participants experienced hospitalization over the 6 months of follow-up (AECOPD group). The baseline clinical characteristics and NPPV-related parameters of these patients were similar to stable group patients not requiring hospitalization (Table 1). 


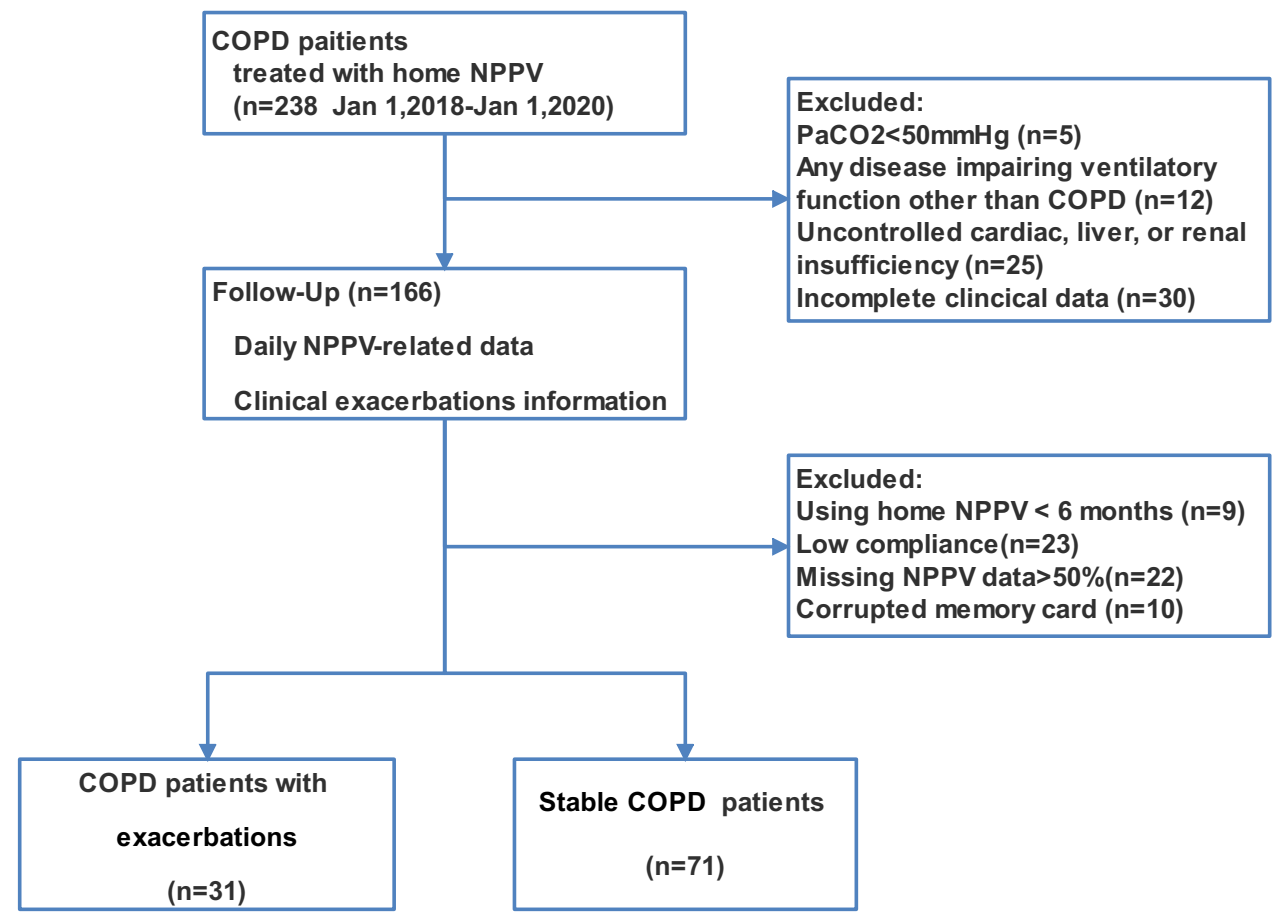

Figure I The study flow chart.

\section{Timing of Changes in Variability of NPPV Parameter Before AECOPD}

Respiratory rate changed significantly from baseline at 1,2 or 3 days prior to admission ( $\mathrm{p}<0.001$, respectively) in the AECOPD group and this was not the case in stable COPD patients when using the 7-day analysis window (Table 2, Figure 2A). Analysis between groups also confirmed that the mean respiratory rate was significantly higher in AECOPD group than stable group during the 3 days that preceded hospitalization, especially on day $-1(22.89 \pm 3.01 / \mathrm{min}$ vs $18.58 \pm 2.09 /$ min, $\mathrm{p}<0.001$ ) (Table 3, Figure 2A).

Other NPPV-related parameters (including daily usage, leaks, and tidal volume) did not change significantly prior to admission in the AECOPD group and there was no significant difference compared with the stable group (Table 2, Table 3, Figure 2B-D). Data of day -7 to -4 are shown in Supplementary Materials Tables S1 and S2.

However, the number of days with abnormal values $(>75$ th or $<25$ th percentile of individual baseline parameters) of those parameters in the AECOPD group were higher than stable group (daily usage, $4.22 \pm 1.80$ vs $2.26 \pm 1.84$; leaks, $4.74 \pm 2.29$ vs $2.69 \pm 1.93$; tidal volume, $5.32 \pm 1.90$ vs $2.42 \pm 1.73 ; \mathrm{p}<0.001$, respectively) during the 7-day pre-AECOPD period.

\section{NPPV Parameters Predicting the Risk of AECOPD}

The results of the univariate logistical analysis are shown in Table 4 and four variables tended to be significant. On multivariate analysis, with results reported as odds ratio (95\% CI), 7-day mean respiratory rate before AECOPD (1.756 [1.249-2.469]), abnormal values of daily use (1.918 [1.253-2.934]) and tidal volume (2.081 [1.380-3.140]) within the 7-day pre-AECOPD period were independently associated with the risk of AECOPD (Table 4).

Correspondingly, ROC analysis demonstrated that area under the curve (AUC) were $0.833,0.773,0.746$, and 0.857 for 7-day mean respiratory rate before AECOPD and abnormal values of daily use, leaks, and tidal volume within the 7-day pre-AECOPD period, respectively (Table 5).

To establish a prediction model based on NPPV parameters, these associated risk factors were used to form an AECOPD risk estimation nomogram (Figure 3A). The nomogram demonstrated good accuracy in predicting a risk of AECOPD (C index: 0.962) and the calibration plots of the nomogram prediction accuracy showed good agreement (mean absolute error $=0.026$ ) (Figure 3B). Furthermore, the ROC curve based on the prediction model was significantly different to that for single parameter (Figure 4). 
Table I Baseline Characteristics of Study Participants

\begin{tabular}{|c|c|c|c|c|}
\hline & Total $(n=102)$ & AECOPD $(n=31)$ & Stable COPD $(n=7 I)$ & $P$ value \\
\hline Age, years & $70.80 \pm 6.86$ & $71.74 \pm 6.55$ & $70.39 \pm 7.00$ & 0.682 \\
\hline Male & $82(80.3 \%)$ & $24(80.6 \%)$ & $58(81.7 \%)$ & 0.190 \\
\hline BMI, $\mathrm{kg} / \mathrm{m}^{2}$ & $21.93 \pm 4.39$ & $22.17 \pm 3.92$ & $21.82 \pm 4.60$ & $0.7 \mid 4$ \\
\hline Former smokers & $83(81.4 \%)$ & $22(71.0 \%)$ & $61(85.9 \%)$ & 0.098 \\
\hline \multicolumn{5}{|l|}{ Comorbidity } \\
\hline Hypertension & $5 \mathrm{I}(50.0 \%)$ & $16(51.6 \%)$ & $35(49.3 \%)$ & 0.830 \\
\hline Diabetes & $16(15.7 \%)$ & $2(6.5 \%)$ & $14(19.7 \%)$ & 0.138 \\
\hline Coronary heart disease & $2 \mathrm{I}(20.6 \%)$ & $4(12.9 \%)$ & $17(23.9 \%)$ & 0.289 \\
\hline Sleep apnea syndrome, & $4(3.9 \%)$ & $2(6.5 \%)$ & $2(2.8 \%)$ & 0.583 \\
\hline Number of AECOPD within the last years & $1.00(1.00-2.00)$ & $1.00(1.00-3.00)$ & $1.00(1.00-2.00)$ & 0.298 \\
\hline FEVI, L & $0.64 \pm 0.29$ & $0.57 \pm 0.17$ & $0.67 \pm 0.33$ & 0.142 \\
\hline FEVI, \% predicted & $25.87 \pm 9.18$ & $24.74 \pm 7.97$ & $26.36 \pm 9.67$ & 0.423 \\
\hline FEVI/FVC, \% & $46.79 \pm 9.92$ & $46.68 \pm 10.49$ & $46.83 \pm 9.75$ & 0.947 \\
\hline $\mathrm{PaO}_{2}, \mathrm{mmHg}$ & $80.03 \pm 30.74$ & $81.03 \pm 28.78$ & $79.59 \pm 31.75$ & 0.830 \\
\hline $\mathrm{PaCO}_{2}, \mathrm{mmHg}$ & $66.80 \pm 12.12$ & $68.64 \pm 12.89$ & $66.00 \pm 11.78$ & 0.314 \\
\hline $\mathrm{HCO}_{3}, \mathrm{mmolL}$ & $37.86 \pm 6.10$ & $36.77 \pm 6.90$ & $38.34 \pm 5.70$ & 0.236 \\
\hline $\mathrm{pH}$ & $7.37 \pm 0.06$ & $7.35 \pm 0.07$ & $7.38 \pm 0.05$ & 0.112 \\
\hline mMRC score & $3.00(2.50-4.00)$ & $3.00(3.00-4.00)$ & $3.00(2.00-4.00)$ & 0.511 \\
\hline IPAP, $\mathrm{cmH}_{2} \mathrm{O}$ & $16.00(15.00-18.00)$ & $16.00(\mid 4.00-17.75)$ & $16.00(\mid 5.00-17.75)$ & 0.545 \\
\hline EPAP, $\mathrm{cmH}_{2} \mathrm{O}$ & $5.00(4.00-5.00)$ & $5.00(4.00-5.00)$ & $5.00(4.00-5.00)$ & 0.668 \\
\hline Back-up rate,/min & $14.00(12.00-15.00)$ & $12.00(12.00-15.00)$ & $14.00(\mid 2.00-15.25)$ & 0.807 \\
\hline \multicolumn{5}{|l|}{ The baseline of NPPV-related parameters } \\
\hline Respiratory rate, breath/min & $18.75 \pm 2.28$ & $18.66 \pm 2.55$ & $18.79 \pm 2.16$ & 0.798 \\
\hline Daily use, $\min /$ day & $429.73 \pm 119.26$ & $425.44 \pm 90.04$ & $431.60 \pm|30.5|$ & 0.811 \\
\hline Leaks, L/min & $37.54 \pm 12.19$ & $37.38 \pm 8.76$ & $37.61 \pm 13.47$ & 0.932 \\
\hline Tidal volume, $\mathrm{mL}$ & $592.68 \pm 136.14$ & $581.63 \pm 140.23$ & $597.50 \pm 135.04$ & 0.590 \\
\hline
\end{tabular}

Note: Data reported as mean or median with SD or interquartile range where appropriate.

Abbreviations: BMI, body mass index; mMRC, modified Medical Research Council; IPAP, inspiratory positive airway pressure; EPAP, expiratory positive airway pressure; NPPV, noninvasive positive pressure ventilation.

\section{Discussion}

In this study, we evaluated the predictive efficiency of dayto-day variation of parameters recorded by the ventilators and have shown that 7-day mean respiratory rate, abnormal values of daily usage, leaks, and tidal volume within a 7-day period might be used to detect changes prior to an AECOPD. Furthermore, we established a multiple parameters prediction model using nomogram.

Respiratory rate is a feasible clinical physiological parameter that may serve as the warning signal of a developing AECOPD and provide useful information on therapeutic interventions response. ${ }^{30}$ Aina et al. ${ }^{10}$ have demonstrated that respiratory rate of COPD patients receiving domiciliary oxygen therapy increased significantly in the days prior to admission due to AECOPD. With regard to data provided by NPPV built-in software, Borel et al. ${ }^{27}$ presented the proof of concept that the risk of AECOPD was increased when respiratory rate and percentage of respiratory cycles triggered by the patient had high values on $\geq 2$ days out of 5 before exacerbation. Blouet et al. ${ }^{28}$ also showed that change in breathing patterns might predict severe AECOPD. In our study, we also found that respiratory rate changed 
Table 2 Timing of Changes in Variability of NPPV-Related Parameter in the Days Before AECOPD (Demonstrated for 7-Day Analysis Windows)

\begin{tabular}{|c|c|c|c|c|c|}
\hline \multirow[t]{2}{*}{ Parameter } & \multirow[t]{2}{*}{ Days \# } & \multicolumn{2}{|c|}{ AECOPD $(n=31)$} & \multicolumn{2}{|c|}{ Stable COPD $(n=7 I)$} \\
\hline & & Difference $(95 \% \mathrm{CI})^{\pi}$ & Adjusted p-value* & Difference $(95 \% \mathrm{CI})^{\pi}$ & Adjusted p-value* \\
\hline $\begin{array}{l}\text { Respiratory rate, breath/ } \\
\text { min }\end{array}$ & $\begin{array}{l}-3 \\
-2 \\
-1\end{array}$ & $\begin{array}{l}2.702 \text { (0.895 to } 4.508) \\
3.386(1.536 \text { to } 5.234) \\
4.224(2.362 \text { to } 6.086)\end{array}$ & $\begin{array}{l}<0.00 I \\
<0.00 I \\
<0.001\end{array}$ & $\begin{array}{l}-0.130(-0.346 \text { to } 0.086) \\
-0.177(-0.393 \text { to } 0.037) \\
-0.203(-0.43 \text { I to } 0.024)\end{array}$ & $\begin{array}{l}0.234 \\
0.103 \\
0.080\end{array}$ \\
\hline Daily use, $\min /$ day & $\begin{array}{l}-3 \\
-2 \\
-1\end{array}$ & $\begin{array}{l}25.510(-56.216 \text { to } \\
107.237) \\
20.394(-74.758 \text { to } \\
115.547) \\
-1.005 \text { ( }-96.335 \text { to } 94.324)\end{array}$ & $\begin{array}{l}0.528 \\
0.664 \\
0.982\end{array}$ & $\begin{array}{l}-2.304(-18.38 \mid \text { to } \\
\text { |3.772) } \\
3.782(-\mid 2.217 \text { to } 19.783) \\
3.77 \mid(-|2.0| \mid \text { to } 19.554)\end{array}$ & $\begin{array}{l}0.775 \\
0.638 \\
0.470\end{array}$ \\
\hline Leaks, L/min & $\begin{array}{l}-3 \\
-2 \\
-1\end{array}$ & $\begin{array}{l}1.669(-2.529 \text { to } 5.869) \\
2.521(-1.516 \text { to } 6.560) \\
2.695(-1.462 \text { to } 6.854)\end{array}$ & $\begin{array}{l}0.423 \\
0.087 \\
0.195\end{array}$ & $\begin{array}{l}-0.848(-2.109 \text { to } 0.412) \\
-0.560(-1.752 \text { to } 0.630) \\
-0.775(-1.900 \text { to } 0.350)\end{array}$ & $\begin{array}{l}0.184 \\
0.350 \\
0.174\end{array}$ \\
\hline Tidal volume, $\mathrm{mL}$ & $\begin{array}{l}-3 \\
-2 \\
-1\end{array}$ & $\begin{array}{l}12.520(-31.189 \text { to } 56.229) \\
19.513(-26.486 \text { to } 65.513) \\
21.900(-27.695 \text { to } 71.497)\end{array}$ & $\begin{array}{l}0.562 \\
0.393 \\
0.374\end{array}$ & $\begin{array}{l}-11.974(-25.943 \text { to } \\
1.994) \\
-7.030(-20.895 \text { to } 6.834) \\
-7.675(-22.206 \text { to } 6.855)\end{array}$ & $\begin{array}{l}0.091 \\
0.315 \\
0.295\end{array}$ \\
\hline
\end{tabular}

Notes: "Day prior to AECOPD admission; " compare each day with the baseline in each group; *adjusted p-value from Dunnett's post hoc test.

significantly from baseline at 1,2 or 3 days prior to admission when using a 7-day analysis window and 7-day mean respiratory rate before AECOPD was independently associated with the risk.

Regarding daily NPPV usage, leaks, and tidal volume, there is no clear picture about the normal variability of patients on NPPV and the relationship with outcomes. ${ }^{22}$ Due to large individual differences, those parameters did not change significantly prior to admission in AECOPD group and there was also no significant difference compared with the stable group in our study. In order to solve this problem, Borel et al. ${ }^{27}$ collected NPPV data from the fourth day of follow-up and updated daily during a stable period which was used for the calculation of the quartiles. For a given day prior to AECOPD, the day was recorded as an abnormal value when the value was $>75$ th or $<25$ th percentile of individual baseline parameters. They found that the variation in daily usage was trending toward statistical significance. In our study, we further demonstrated that abnormal values of daily use and tidal volume within the 7-day pre-AECOPD period were independently associated with the risk of AECOPD. Such difference can be explained by the study design. Borel et al. ${ }^{27}$ prospectively identified all AECOPD events regardless of severity using the EXACT-Pro questionnaire ${ }^{9}$ every day, which might include some moderate exacerbations. In our study, we aimed to identify severe AECOPD and the date of severe AECOPD was defined as the date of admission. These analytical methods and results can be explained by the hypothesis that individual stable NPPV-related parameters of patients were developed during the clinical stable state period and abnormal values compared with stable state might be a warning indicator to predict the onset of AECOPD. For daily usage, some patients could respond to a clinical exacerbation either by increasing daily usage to reduce breathlessness or by decreasing use due to phlegm, cough, or intolerance and inadequacy of the device, with the preset settings unsuitable for a clinical exacerbation period. Abnormal value of tidal volume might increase as patients could respond to a clinical deterioration, probably with the expectation of relief of dyspnea. High-value of leaks also might increase in the days preceding exacerbation onset, which influence the alveolar ventilation and sleep quality. ${ }^{22}$

As noted above, the mean respiratory rate was significantly higher in the AECOPD group than the stable group during the 3 days that preceded hospitalization, especially on day -1 (mean respiratory rate of the period from day -7 to -1$)$. We also found the number of days with abnormal value of daily usage, leaks, and tidal volume in AECOPD group were higher than stable group. To establish a multiple NPPV-related parameters prediction model, a nomogram was constructed by combining four risk 

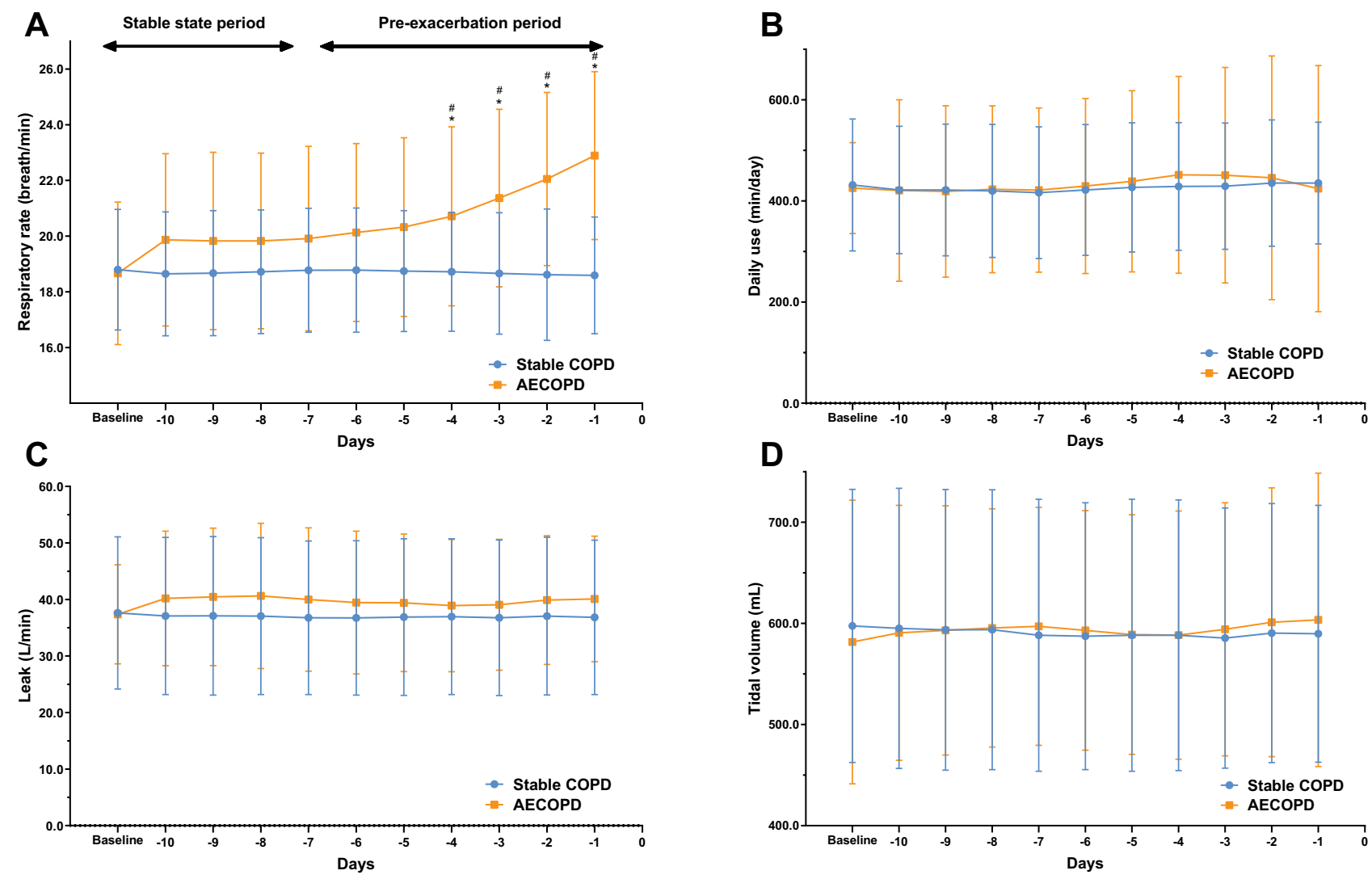

Figure 2 Timing of changes in variability of NPPV parameter before AECOPD. (A) Respiratory rate; (B) daily usage; (C) leaks; (D) tidal volume. Data reported as mean with SD.

Notes: *p-value from difference between each day with the baseline in each group $<0.05$. ${ }^{*}$-value from difference between AECOPD and Stable COPD group $<0.05$.

factors of AECOPD. For clinical use of the model, the ROC curve based on the prediction model was significantly different to that for a single parameter. To our knowledge, no previous study has explored the prediction model of AECOPD based on day-to-day NPPV-related parameters. The use of the nomogram in detecting exacerbations of ventilator-dependent patients to direct clinical management is a new concept and our results open the opportunity of exploring a multiple NPPV-related parameters prediction model. More research is needed to confirm these results and to assess their clinical usefulness.

With more reliable telemonitoring and transmission of clinical parameters from home to clinical setting, ${ }^{26}$ effective management strategies involved telemonitoring to detect exacerbation early are attractive. ${ }^{20}$ Our results offer a window of possibility for therapeutic intervention triggered by this method to reduce the frequency or severity of a fullblown episode of AECOPD. In the future, telemonitoring for COPD may involve the use of personalized algorithms including more NPPV-related data to estimate exacerbations and facilitate appropriate feedback management. ${ }^{31}$

\section{Limitation}

Our study had some limitations. First, our findings might be limited by the sample size and single institution retrospective cohort study. It is necessary to validate the results from other centers and larger prospective studies. Second, only internal verification of the nomogram was performed and external verification will be required in further studies. Third, the date of admission might not be equal to the time of symptom deterioration. Some prospective studies used the EXACT-Pro symptoms questionnaire every day ${ }^{27}$ or weekly telephone interview ${ }^{14}$ to detect exacerbation events. Our prediction model did not include some early moderate AECOPD events, which might affect clinical usefulness of early prediction. Fourth, the median NPPV setting in our study was an IPAP of $16 \mathrm{~cm} \mathrm{H}_{2} \mathrm{O}$, which was less than in recent randomized controlled trials. With more effective pressure support fewer patients may be admitted to a hospital and as a consequence the finding may be different. Fifth, we did not have the compliance information of pharmacological therapy at home, which is a factor of AECOPD. It might influence the result of our study. Finally, because the 
Table 3 Comparison of Parameter Recorded by NPPV Software in the Days Before AECOPD Between AECOPD Group and Stable Group (Demonstrated for 7-Day Analysis Windows)

\begin{tabular}{|c|c|c|c|c|c|}
\hline Parameter & Day\# & AECOPD $(n=3 I)$ & Stable COPD $(n=7 I)$ & Difference $(95 \% \mathrm{CI})^{*}$ & P-value \\
\hline \multirow[t]{3}{*}{ Respiratory rate, breath/min } & -3 & $21.36 \pm 3.18$ & $18.66 \pm 2.18$ & 2.705 (1.627 to 3.784$)$ & $<0.001$ \\
\hline & -2 & $22.05 \pm 3.10$ & $18.61 \pm 2.12$ & 3.437 (2.386 to 4.488$)$ & $<0.001$ \\
\hline & -1 & $22.89 \pm 3.01$ & $18.58 \pm 2.09$ & 4.301 (3.272 to 5.330$)$ & $<0.001$ \\
\hline \multirow[t]{3}{*}{ Daily use, $\mathrm{min} / \mathrm{day}$} & -3 & $450.95 \pm 213.19$ & $429.30 \pm 124.82$ & 21.653 (-45.255 to 88.562$)$ & 0.522 \\
\hline & -2 & $445.83 \pm 240.97$ & $435.38 \pm 124.83$ & $10.449(-61.436$ to 82.336$)$ & 0.820 \\
\hline & -1 & $424.43 \pm 243.39$ & $435.37 \pm 120.37$ & $-10.938(-82.296$ to 60.419$)$ & 0.813 \\
\hline \multirow[t]{3}{*}{ Leaks, L/min } & -3 & $39.05 \pm 11.57$ & $36.76 \pm 13.76$ & $2.294(-3.318$ to 7.907$)$ & 0.419 \\
\hline & -2 & $39.90 \pm 11.38$ & $37.05 \pm 13.95$ & $2.858(-2.793$ to $8.5 \mathrm{II})$ & 0.318 \\
\hline & -1 & $40.08 \pm 11.12$ & $36.83 \pm 13.65$ & 3.247 ( -2.283 to 8.777$)$ & 0.246 \\
\hline \multirow[t]{3}{*}{ Tidal volume, $\mathrm{mL}$} & -3 & $594.15 \pm 125.20$ & $585.52 \pm 128.65$ & $8.625(-45.884$ to 63.135$)$ & 0.752 \\
\hline & -2 & $601.14 \pm 132.94$ & $590.47 \pm \mid 28.11$ & $10.675(-44.670$ to 66.020$)$ & 0.702 \\
\hline & -1 & $603.53 \pm 144.99$ & $589.82 \pm|27.0|$ & I3.707 (-42.954 to 70.369$)$ & 0.632 \\
\hline
\end{tabular}

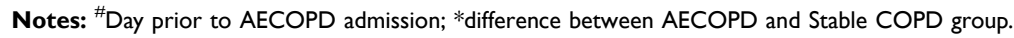

Table 4 Univariate and Multivariate Logistic Regression Analysis of Changes in NPPV Parameters Associated with the Risk of Exacerbation

\begin{tabular}{|c|c|c|c|c|}
\hline Variable & Crude OR* $(95 \% \mathrm{CI})$ & p value & Adjusted $\mathrm{OR}^{\#}(95 \% \mathrm{Cl})$ & p value \\
\hline 7-day mean Respiratory rate & I.849(I.408 to 2.428$)$ & $<0.001$ & I.756(I.249 to 2.469$)$ & 0.001 \\
\hline Abnormal value of daily use within 7-day & $1.706(1.320$ to 2.206$)$ & $<0.001$ & $1.918(1.253$ to 2.934$)$ & 0.003 \\
\hline Abnormal value of leaks within 7-day & $1.567(1.255$ to 1.958$)$ & $<0.001$ & I.27I(0.873 to I.852) & 0.210 \\
\hline Abnormal value of tidal volume within 7-day & $2.165(1.607$ to 2.915$)$ & $<0.001$ & $2.08 I(1.380$ to 3.140$)$ & $<0.001$ \\
\hline
\end{tabular}

Notes: *Univariate logistic regression analysis; \#multivariate logistic regression analysis.

Table 5 Receiver Operating Characteristic Analysis of NPPV Parameters to Predict AECOPD

\begin{tabular}{|l|l|l|l|l|l|}
\hline Variable & AUC $(\mathbf{9 5} \% \mathbf{~ C I})$ & P-value & Cutoff value & Sensitivity & Specificity \\
\hline 7-day mean Respiratory rate & $0.833(0.749$ to 0.917$)$ & $<0.001$ & 19.5 & 0.935 & 0.648 \\
\hline Abnormal value of daily use within 7-day & $0.773(0.683$ to 0.683$)$ & $<0.001$ & 2.5 & 0.806 & 0.606 \\
\hline Abnormal value of leaks within 7-day & $0.746(0.636$ to 0.855$)$ & $<0.001$ & 4.5 & 0.612 & 0.817 \\
\hline Abnormal value of tidal volume within 7-day & $0.857(0.774$ to 0.941$)$ & $<0.001$ & 3.5 & 0.838 & 0.761 \\
\hline
\end{tabular}

Abbreviation: AUC, area under the curve.

model was based on basic NPPV-related data, more specific markers might further improve the accuracy. For example, nocturnal $\mathrm{PaCO}_{2}$ is an essential to monitor the quality of alveolar ventilation and transcutaneous carbon dioxide tension can be considered as a reasonable method for evaluating alveolar hypoventilation and exacerbations. ${ }^{32}$ Also, the end-tidal carbon dioxide partial pressure suitable for NIV will be a convenient module of telemonitoring in the future.

\section{Conclusion}

In summary, 7-day mean respiratory rate, abnormal values of daily usage, leaks, and tidal volume within the 7-day pre-AECOPD period may be biomarkers for detection of AECOPD. By combining those NPPV parameters, a model provides better estimation of exacerbation in COPD patients with home NPPV. Our results provide further insight into the day-to-day variability of parameters 
A

Points

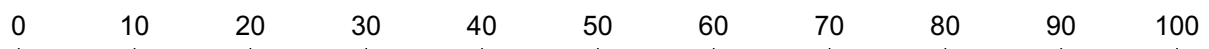

Abnormal value of daily use within 7-day

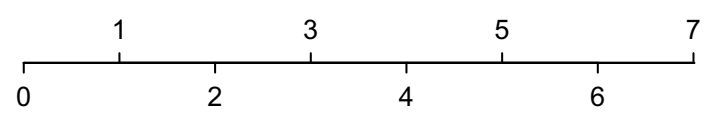

Abnormal value of leaks within 7-day

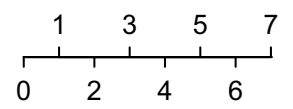

Abnormal value of tidal volume within 7-day

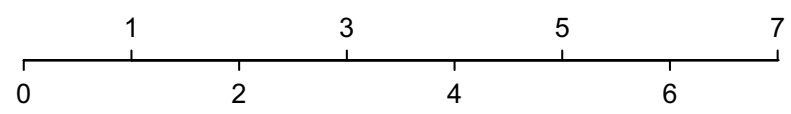

7-day mean

Respiratory rate

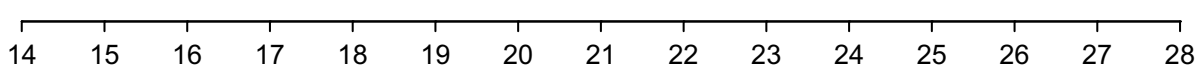

Total Points

\begin{tabular}{|c|c|c|c|c|c|c|c|c|c|c|c|}
\hline & 7 & 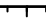 & $T$ & 1 & 11 & 1 & 1 & 7 & 7 & 11 & $1+1$ \\
\hline 0 & 20 & 40 & 60 & 80 & 100 & 120 & 140 & 160 & 180 & 200 & 220 \\
\hline
\end{tabular}

AECOPD rate

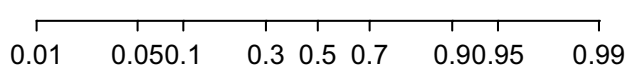

B

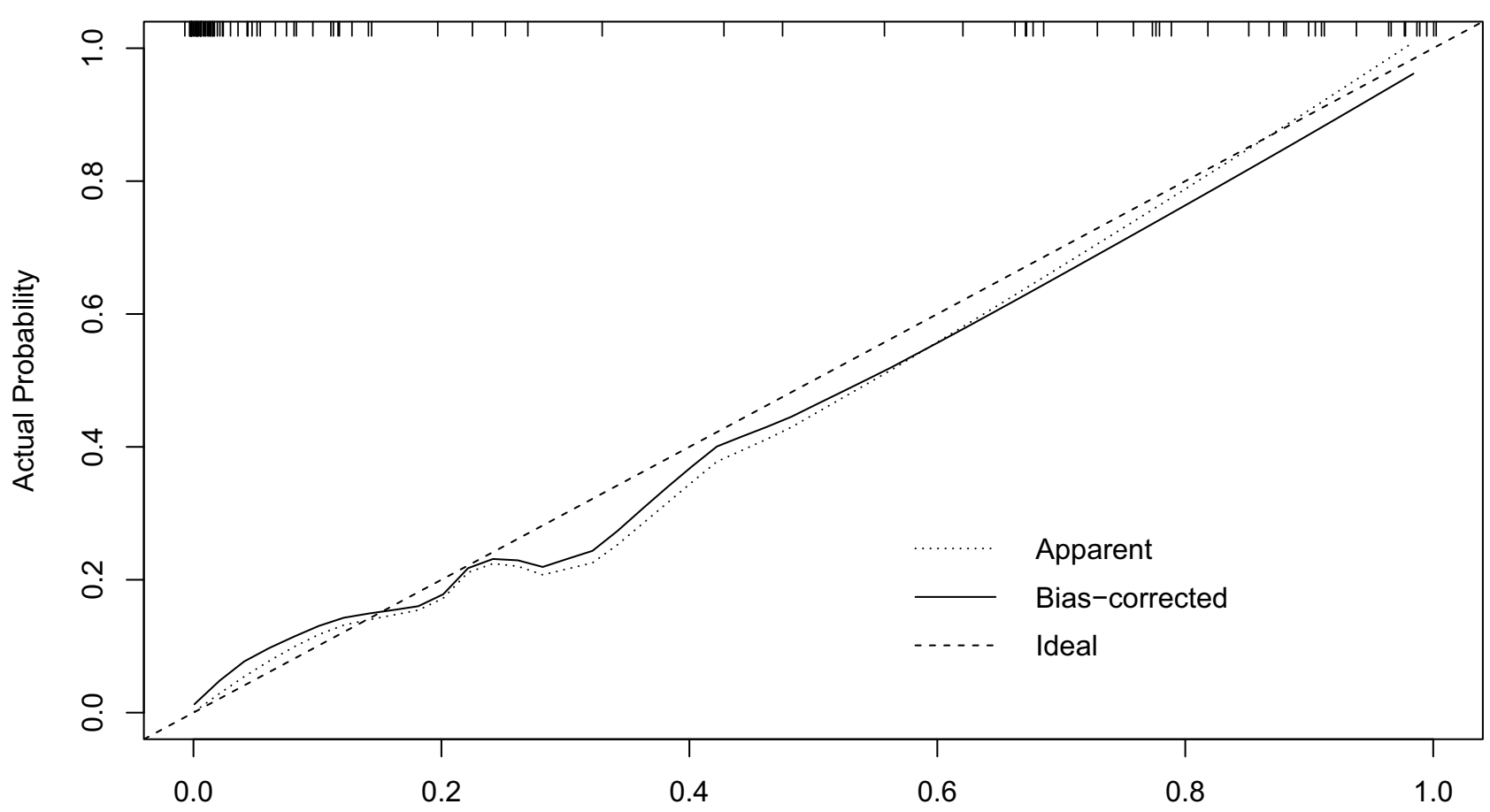

Predicted $\operatorname{Pr}\{A E C O P D=1\}$

$B=1000$ repetitions, boot

Mean absolute error $=0.026 n=102$

Figure 3 Nomogram for AECOPD risk and its predictive performance. (A) Nomogram to estimate the risk of AECOPD based on NPPV-related parameters. (B) Internal validity of the predictive performance of the nomogram in using the bootstrap validation method. 


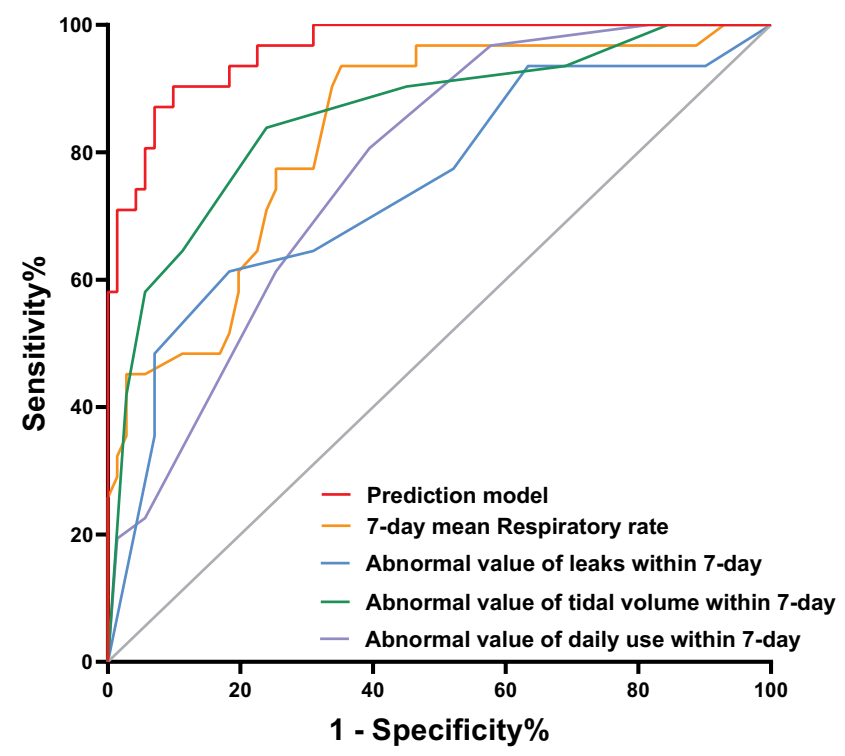

Figure 4 Receiver operating characteristic curves for predicting the risk of AECOPD.

recorded by home NPPV prior to AECOPD, which offer an opportunity for telemonitoring and early intervention.

\section{Acknowledgments}

This study was supported by The National key R\&D plan (2020YFC2003700), National Natural Science Foundation of China (81630001, 81770075, 82041003), Science and Technology Commission of Shanghai Municipality (20411950402, 20Z11901000, 20XD1401200), Shanghai Municipal Key Clinical Specialty (shslczdzk02201) and Natural Science Foundation of China (Nos. 81770039 and 82070045).

\section{Disclosure}

The authors report no conflicts of interest in this work.

\section{References}

1. Wedzicha JA, Seemungal TA. COPD exacerbations: defining their cause and prevention. Lancet. 2007;370(9589):786-796. doi:10.1016/ S0140-6736(07)61382-8

2. Hurst JR, Wedzicha JA. What is (and what is not) a COPD exacerbation: thoughts from the new GOLD guidelines. Thorax. 2007;62 (3):198-199. doi:10.1136/thx.2007.077883

3. Hoogendoorn M, Hoogenveen RT, Rutten-van Mölken MP, Vestbo J, Feenstra TL. Case fatality of COPD exacerbations: a meta-analysis and statistical modelling approach. Eur Respir J. 2011;37(3):508-515. doi:10.1183/09031936.00043710

4. Hurst JR, Vestbo J, Anzueto A, et al. Susceptibility to exacerbation in chronic obstructive pulmonary disease. $N$ Engl J Med. 2010;363 (12):1128-1138. doi:10.1056/NEJMoa0909883
5. Soler-Cataluña JJ, Martínez-García MA, Román Sánchez P, Salcedo E, Navarro M, Ochando R. Severe acute exacerbations and mortality in patients with chronic obstructive pulmonary disease. Thorax. 2005;60(11):925-931. doi:10.1136/thx.2005.040527

6. Khakban A, Sin DD, FitzGerald JM, et al. Ten-year trends in direct costs of COPD: a Population-Based Study. Chest. 2015;148 (3):640-646. doi:10.1378/chest.15-0721

7. Wilkinson TM, Donaldson GC, Hurst JR, Seemungal TA, Wedzicha JA. Early therapy improves outcomes of exacerbations of chronic obstructive pulmonary disease. Am J Respir Crit Care Med. 2004;169(12):1298-1303. doi:10.1164/rccm.200310-1443OC

8. Seemungal TA, Donaldson GC, Bhowmik A, Jeffries DJ, Wedzicha JA. Time course and recovery of exacerbations in patients with chronic obstructive pulmonary disease. Am J Respir Crit Care Med. 2000;161(5):1608-1613. doi:10.1164/ajrccm.161.5.9908022

9. Leidy NK, Wilcox TK, Jones PW, Roberts L, Powers JH, Sethi S. Standardizing measurement of chronic obstructive pulmonary disease exacerbations. Reliability and validity of a patient-reported diary. $\mathrm{Am}$ J Respir Crit Care Med. 2011;183(3):323-329. doi:10.1164/ rccm.201005-0762OC

10. Yañez AM, Guerrero D, Pérez de Alejo R, et al. Monitoring breathing rate at home allows early identification of COPD exacerbations. Chest. 2012;142(6):1524-1529. doi:10.1378/chest.11-2728

11. Hurst JR, Donaldson GC, Quint JK, Goldring JJ, Patel AR, Wedzicha JA. Domiciliary pulse-oximetry at exacerbation of chronic obstructive pulmonary disease: prospective pilot study. BMC Pulm Med. 2010;10(1):52. doi:10.1186/1471-2466-10-52

12. Miłkowska-Dymanowska J, Białas AJ, Obrębski W, Górski P, Piotrowski WJ. A pilot study of daily telemonitoring to predict acute exacerbation in chronic obstructive pulmonary disease. Int $J$ Med Inform. 2018;116:46-51. doi:10.1016/j.jimedinf.201 8.04.013

13. Fernandez-Granero MA, Sanchez-Morillo D, Leon-Jimenez A. Computerised analysis of telemonitored respiratory sounds for predicting acute exacerbations of COPD. Sensors. 2015;15 (10):26978-26996. doi:10.3390/s151026978

14. Zimmermann SC, Huvanandana J, Nguyen CD, et al. Day-to-day variability of forced oscillatory mechanics for early detection of acute exacerbations in COPD. Eur Respir J. 2020;56(3):1901739. doi:10.1183/13993003.01739-2019

15. Vianello A, Fusello M, Gubian L, et al. Home telemonitoring for patients with acute exacerbation of chronic obstructive pulmonary disease: a randomized controlled trial. BMC Pulm Med. 2016;16 (1):157. doi:10.1186/s12890-016-0321-2

16. Segrelles Calvo G, Gómez-Suárez C, Soriano JB, et al. A home telehealth program for patients with severe COPD: the PROMETE study. Respir Med. 2014;108(3):453-462. doi:10.1016/j.rmed.20 13.12.003

17. Ringbæk T, Green A, Laursen LC, Frausing E, Brøndum E, Ulrik CS. Effect of tele health care on exacerbations and hospital admissions in patients with chronic obstructive pulmonary disease: a randomized clinical trial. Int J Chron Obstruct Pulmon Dis. 2015;10:1801-1808. doi:10.2147/COPD.S85596

18. Pinnock H, Hanley J, McCloughan L, et al. Effectiveness of telemonitoring integrated into existing clinical services on hospital admission for exacerbation of chronic obstructive pulmonary disease: researcher blind, multicentre, randomised controlled trial. $B M J$. 2013;347(oct17 3):f6070. doi:10.1136/bmj.f6070

19. Chatwin M, Hawkins G, Panicchia L, et al. Randomised crossover trial of telemonitoring in chronic respiratory patients (TeleCRAFT trial). Thorax. 2016;71(4):305-311. doi:10.1136/thoraxjnl-2015-207045

20. Walker PP, Pompilio PP, Zanaboni P, et al. Telemonitoring in Chronic Obstructive Pulmonary Disease (CHROMED). A Randomized Clinical Trial. Am J Respir Crit Care Med. 2018;198(5):620-628. doi:10.1164/rccm.201712-2404OC 
21. Macrea M, Oczkowski S, Rochwerg B, et al. Long-term noninvasive ventilation in chronic stable hypercapnic chronic obstructive pulmonary disease. an official american thoracic society clinical practice guideline. Am J Respir Crit Care Med. 2020;202(4):e74-e87. doi:10.1164/rccm.202006-2382ST

22. Ergan B, Oczkowski S, Rochwerg B, et al. European Respiratory Society guidelines on long-term home non-invasive ventilation for management of COPD. Eur Respir J. 2019;54(3):1901003. doi:10.1183/13993003.01003-2019

23. Murphy PB, Rehal S, Arbane G, et al. Effect of home noninvasive ventilation with oxygen therapy vs oxygen therapy alone on hospital readmission or death after an acute COPD exacerbation: a randomized clinical trial. JAMA. 2017;317(21):2177-2186. doi:10.1001/jama.2017.4451

24. Wilson ME, Dobler CC, Morrow AS, et al. Association of home noninvasive positive pressure ventilation with clinical outcomes in chronic obstructive pulmonary disease: a systematic review and meta-analysis. JAMA. 2020;323(5):455-465. doi:10.1001/ jama.2019.22343

25. 2021 global strategy for prevention, diagnosis and management of COPD; 2020. https:/goldcopd.org/2021-gold-reports/. Accessed March 11, 2021.

26. Ambrosino N, Vitacca M, Dreher M, et al. Tele-monitoring of ventilator-dependent patients: a European Respiratory Society Statement. Eur Respir J. 2016;48(3):648-663. doi:10.1183/ 13993003.01721-2015
27. Borel JC, Pelletier J, Taleux N, et al. Parameters recorded by software of non-invasive ventilators predict COPD exacerbation: a proof-ofconcept study. Thorax. 2015;70(3):284-285. doi:10.1136/thoraxjnl2014-206569

28. Blouet S, Sutter J, Fresnel E, Kerfourn A, Cuvelier A, Patout M. Prediction of severe acute exacerbation using changes in breathing pattern of COPD patients on home noninvasive ventilation. Int J Chron Obstruct Pulmon Dis. 2018;13:2577-2586. doi:10.2147/COPD.S170242

29. Celli BR, Wedzicha JA. Update on clinical aspects of chronic obstructive pulmonary disease. $N$ Engl $J$ Med. 2019;381 (13):1257-1266. doi:10.1056/NEJMra1900500

30. Murphy PB, Kumar A, Reilly C, et al. Neural respiratory drive as a physiological biomarker to monitor change during acute exacerbations of COPD. Thorax. 2011;66(7):602-608. doi:10.1136/ thx.2010.151332

31. Pinnock H, McKinstry B. Telehealth for chronic obstructive pulmonary disease: promises, populations, and personalized care. $\mathrm{Am}$ J Respir Crit Care Med. 2018;198(5):552-554. doi:10.1164/ rccm.201803-0560ED

32. Janssens J-P, Borel J-C, Pépin J-L. Nocturnal monitoring of home non-invasive ventilation: the contribution of simple tools such as pulse oximetry, capnography, built-in ventilator software and autonomic markers of sleep fragmentation. Thorax. 2011;66(5):438-445. doi:10.1136/thx.2010.139782

\section{Publish your work in this journal}

The International Journal of COPD is an international, peer-reviewed journal of therapeutics and pharmacology focusing on concise rapid reporting of clinical studies and reviews in COPD. Special focus is given to the pathophysiological processes underlying the disease, intervention programs, patient focused education, and self managemen protocols. This journal is indexed on PubMed Central, MedLine and CAS. The manuscript management system is completely online and includes a very quick and fair peer-review system, which is all easy to use. Visit http://www.dovepress.com/testimonials.php to read real quotes from published authors. 